\title{
ARTICLE
}

Maternal and pediatric nutrition

\section{Breastfeeding and maternal eating behaviours are associated with child eating behaviours: findings from the ROLO Kids Study}

\author{
Cara A. Yelverton $\mathbb{1}^{1} \cdot$ Aisling A. Geraghty $\mathbb{D}^{1} \cdot$ Eileen C. O'Brien ${ }^{1} \cdot$ Sarah Louise Killeen ${ }^{1} \cdot$ Mary K. Horan ${ }^{1}$. \\ Jean M. Donnelly ${ }^{1}$. Elizabeth Larkin $\mathbb{1}^{1} \cdot$ John Mehegan $^{2} \cdot$ Fionnuala M. McAuliffe $\mathbb{( I}^{1}$
}

Received: 2 December 2019 / Revised: 6 August 2020 / Accepted: 22 September 2020 / Published online: 30 September 2020

(c) The Author(s) 2020. This article is published with open access

\begin{abstract}
Background Child eating behaviours can negatively contribute to the development of childhood obesity. This study investigated associations between breastfeeding habits, maternal eating behaviours and child eating behaviours, in 5-year-old children.

Methods Secundigravida women were recruited to the ROLO dietary randomised controlled trial (Dublin, Ireland) and were followed up with their children to 5 years of age. Breastfeeding exposure and duration were obtained at postnatal and infant follow-up at 2 and 6 months and 2 and 5 years. At 5 years, maternal and child eating behaviours were measured using the Three Factor Eating Questionnaire and the Child Eating Behaviour Questionnaire, respectively. Regression determined associations between breastfeeding habits and maternal eating behaviours with child eating behaviours, controlling for RCT group, maternal education level, maternal BMI at 5 years, childcare exposure and child BMI centile at 5-year follow-up. Results There were 230 mother and child pairs analysed. One hundred and fifty-eight mothers had initiated breastfeeding. Median breastfeeding duration was 22 (IQR 33) weeks. Children who were never breastfed were more likely to express a desire to drink $(B=-1.01, p=0.022)$. Longer breastfeeding duration was associated with lower food responsiveness $(B=$ $-1.71, p=0.003)$. Maternal uncontrolled eating was positively associated with child food responsiveness, emotional overeating and emotional undereating $(B=0.21, p<0.001 ; B=0.14, p=0.005 ; B=0.14, p=0.005$, respectively). Maternal emotional eating was associated with child emotional overeating and undereating $(B=0.27, p<0.001, B=0.29$, $p=0.004$, respectively).

Conclusion Not breastfeeding and short breastfeeding duration may contribute to the development of obesogenic eating behaviours in children, alongside maternal eating behaviours including uncontrolled and emotional eating. These 'food approach' eating behaviours may increase risk of overweight/obesity as they are associated with increased energy intake, hence the importance of research surrounding eating behaviours.
\end{abstract}

\section{Introduction}

Childhood obesity is a global issue. Ireland is no exception with one in five Irish children aged 5-12 years having overweight or obesity [1]. This indicates a minor improvement from the National Children's Food Survey in

Fionnuala M. McAuliffe

fionnuala.mcauliffe@ucd.ie

1 UCD Perinatal Research Centre, School of Medicine, University College Dublin, National Maternity Hospital, Dublin, Ireland

2 UCD School of Public Health, Physiotherapy and Sports Science, University College Dublin, Belfield, Dublin 4, Ireland
2003-2004 [2], at which point one in four children had overweight/obesity. However, the issue of obesity among Irish children remains and needs to be addressed.

Child eating behaviours are known to play a role in the aetiology of obesity. Child eating behaviours and their relationships with weight status have been reported in a number of populations globally. The Generation R Study found increased uncontrolled responses to food and food enjoyment to be associated with increased BMI in 4-yearold Dutch children [3]. The GUSTO study found a desire to drink and food enjoyment to be associated with increased weight status in 5 and 6 years old [4]. Finally the PEACHES and TEDS study were combined to show the impact of eating behaviours on child weight status at 7-9 years and 9-12 years old, respectively. Enjoyment of food, desire to 
drink and food responsiveness were associated with overweight in children [5]. Understanding the early life factors that affect these behaviours therefore may help us identify areas for intervention to curb the progression of overweight and obesity in children.

Breastfeeding is the optimum method of infant feeding as it has a plethora of short and long-term benefits for mothers and children. Therefore, the World Health Organisation (WHO) recommends exclusive breastfeeding for 6 months to all women globally, and to continue breastfeeding for minimum 2 years in conjunction with the introduction of safe, complimentary foods [6]. Despite this, in the WHO European region, from 2006 to 2012, only $25 \%$ infants were breastfed for 6 months, compared to a global rate of $40 \%$ [7]. Ireland has the lowest breastfeeding rates in this region in 2017 with $46.2 \%$ of infants not being breastfed, and similarly lowest rates of infants exclusively breastfed for 6 months at $10.5 \%$ [7].

A recent review by Ventura [8] discusses the importance of breastfeeding in establishing food preferences. Infants are born with an innate preference for sweet tastes, and are exposed to a variety of flavours while being breastfed, further influencing infant food preferences while weaning. Majority of previous studies have investigated food preferences, dietary intakes and their role in the aetiology of obesity. Child eating behaviours also hold importance, yet there is little research investigating breastfeeding and eating behaviours, such as food neophobia and picky eating [911]. Research regarding breastfeeding and picky eating remains equivocal. Studies such as the Generation R Study in the Netherlands and the Healthy Start Primary Intervention Study in Denmark have found a relationship in which prolonged breastfeeding is associated with decreased picky eating $[10,11]$. However, the ALSPAC study found no evidence to suggest maintaining breastfeeding for a longer duration has any impact on fussy eating habits [12]. Similarly, McDermott et al. [13] found no association between breastfeeding practices and fussy eating habits in children aged 2-4 years. Research including behaviours other than food fussiness has suggested a protective effect of breastfeeding against obesogenic eating behaviours but calls for further analysis to confirm this association [14]. Clearly the aetiology of these behaviours is complex, requiring ongoing research for any consensus to be formed.

Parents have a major impact on a child's eating behaviour through choosing the infant feeding practice, being the main providers of foods available and their interaction with their children during mealtimes [15]. A parent's control over their child's eating behaviour has previously been determined to occur via restriction and pressure feeding practices, which can have negative impacts on weight $[16,17]$. Similarities between parent and adolescent eating behaviours have been observed in previous research $[18,19]$.
Whether parental eating behaviour is something a young child emulates when developing their own eating behaviour remains to be explored.

In order to address the existing gaps in the literature, the aim of this study is to investigate if a relationship exists between breastfeeding practices and maternal eating behaviours, with child eating behaviours in 5-year-old children. The author's hypothesise that breastfeeding will encourage healthful eating behaviours, and that children will to some extent mirror their parent's eating behaviours.

\section{Study design and methods}

\section{Population}

This is a secondary analysis of the ROLO RCT, a Randomised cOntrol trial of LOw glycaemic index (GI) diet in pregnancy to prevent recurrence of macrosomia (birthweight $>4 \mathrm{~kg}$ ) in euglycemic women [20]. The ROLO RCT was carried out in the National Maternity Hospital (NMH), Dublin, Ireland. Ethical approval for this study was granted by the Ethics Committee of the NMH. The background, methods and results of this study have been published previously [21]. Participants consisted of secundigravida women, having previously given birth to a macrosomic baby, with no history of gestational diabetes or conditions requiring medication. Seven hundred and fifty-one participants were randomised to receive low GI dietary advice vs. usual care (no dietary advice) to reduce recurrence of macrosomia. Primary outcome was birthweight and secondary outcome was gestational weight gain and glucose intolerance. No difference was noted in birthweight, though significant maternal benefits were found in terms of less gestational weight gain and improved glucose tolerance [21]. These women were followed throughout pregnancy, birth and up to 5-year postnatally.

Mothers were contacted and invited to take part in the ROLO Kids follow-up study when their study child reached 5 years of age. Participants were eligible for the follow-up if their child had not yet reached 5 years and 6 months and gave fully informed written consent. Four hundred and three mother-child dyads returned for the 5-year follow-up. Of these, 230 pairs had data on mother and child eating behaviours and breastfeeding habits.

\section{Breastfeeding practices}

Mothers reported breastfeeding duration retrospectively at 6 months, 2 years and 5 years postnatally. At each of these time points, mothers reported whether they had ever breastfed, and the duration in weeks that they breastfed for. A composite of answers given at each time point was used 
to dichotomise participants as breastfed vs. never breastfed as a measure of breastfeeding exposure, defined as 'did you ever breastfeed your child'. A composite of breastfeeding duration was also determined for breastfeeding duration in weeks. Mothers that did not attend the 6-month follow-up but answered at 5 years could be included by using data reported at 5 years. If mothers had answered at an early time point, this was used instead of the duration reported at later time points to reduce memory bias.

\section{Assessment of eating behaviours}

The Three Factor Eating Questionnaire (TFEQ) was used to determine maternal eating behaviours. This questionnaire was developed by Stunkard and Messick [22] and has been previously determined suitable in measuring eating behaviours [23, 24]. The TFEQ measures three different areas of behaviour: Uncontrolled Eating, Cognitive Restraint and Emotional Eating. Uncontrolled Eating represents the inability to resist foods when they are tempted, or if they are in the company of people enjoying a meal (Cronbach $\alpha=$ 0.854). Cognitive Restraint is indicative of individuals that make a conscious effort to avoid certain foods or not finish meals, with a goal of losing weight (Cronbach $\alpha=0.708$ ). Emotional Eating occurs when a mother eats more than usual due to generally negative emotions, e.g., anxiety (Cronbach $\alpha=0.886$ ). Mothers answered the TFEQ in relation to their own eating behaviour using a four-point Likert scale from definitely false to definitely true, almost never to almost always, unlikely to very likely, only at mealtimes to almost always and never to at least once a week, depending on the question. A higher score indicated the mother was more likely to experience this eating behaviour.

The Child Eating Behaviour Questionnaire (CEBQ) was used to describe child eating behaviours. The CEBQ was developed by Wardle et al. [25], 'to provide a useful measure of eating style for research into the early precursors of obesity or eating disorders'. The CEBQ has been validated as an accurate measurement of child eating behaviours [2628]. The CEBQ determines whether a child has a food approach behaviour or food avoidance behaviour. Both outcomes have four subsets. The food approach behaviour subset has been associated with increased weight status, and includes Food Responsiveness (inappropriate responses to the food environment around them, e.g., if allowed, my child would eat too much; Cronbach $\alpha=0.811$ ), Enjoyment of Food (is the child enjoying mealtimes and curious about food, e.g., my child is interested in food; Cronbach $\alpha=$ 0.888), Emotional Overeating (implies increased food intake during times of negative emotions, e.g., my child eats more when worried; Cronbach $\alpha=0.691$ ) and a Desire to Drink (implies the desire to have a drink frequently, sometimes sugar sweetened, e.g., my child is always asking for a drink; Cronbach $\alpha=0.863$ ) [25]. The food avoidance behaviour subsets include Slowness in Eating (taking a very long time to finish meals, e.g., my child takes more than 30 min to finish a meal; Cronbach $\alpha=0.791$ ), Satiety Responsiveness (ability to stop eating when the feeling of fullness occurs, e.g., my child gets full before they finish a meal; Cronbach $\alpha=0.777$ ), Food Fussiness (another term for picky eating, e.g., my child is difficult to please with meals; Cronbach $\alpha=0.928$ ) and Emotional Undereating (indicates a reduced intake of food during periods of emotional distress, e.g., my child eats less when angry; Cronbach $\alpha=0.766)$. Each question contributes to one of the above behaviours. The mother completed the questionnaire using a five-point Likert scale from never to always; a higher score indicates the child is more likely to express this behaviour.

\section{Demographic information}

Baseline characteristics were also recorded and adjusted for within the analysis. Maternal ethnicity and education level were recorded at recruitment into the ROLO study. Thirdlevel education was dichotomised into those with or without third-level education (third level being universities, institutes of technology and colleges of education). Maternal and child BMI $\left(\mathrm{kg} / \mathrm{m}^{2}\right)$ was determined using height and weight measured by trained research nutritionists at the 5year-old follow-up, rounded to the nearest $0.1 \mathrm{~kg}$. The child's exact age was calculated based on date of appointment. Birthweight was recorded during original ROLO pregnancy study. Type of childcare, such as family member at home, family member outside the home, creche, no childcare, etc., was recorded at the 5-year follow-up and noted as exposed or not exposed to childcare. Child birthweight centiles were calculated using Gestation Network's Bulk Calculator 6.2.3 UK [29]. For the 5-year-old BMI centiles, they were calculated relevant to the $1990 \mathrm{UK}$ reference data, using the Excel LMS Growth macro [30].

\section{Statistical analysis}

Statistical Package for the Social Sciences (Version 24) was used for statistical analysis. Histograms were used for visual aid in determining normality in each of the variables-all eating behaviour variables were considered normally distributed and so parametric analysis measurements were used. The following descriptors were found to be skewed and so median and interquartile range were reported; maternal BMI, breastfeeding duration in weeks, child age, child birthweight centile, and child BMI centile at 5 years. Breastfeeding duration in weeks was $\log 10$ transformed prior to use in regression models. 
The cohort was split into infants never exposed to breastfeeding and infants who had been exposed to any breastfeeding. Differences in child eating behaviours between these groups were measured using Student's $t$ tests. Multiple regression was carried out with breastfeeding exposure (ever breastfed vs. no breastfeeding) as a predictor of child eating behaviours, adjusted for RCT group, maternal education level, maternal BMI, childcare exposure (attended any form of childcare vs. no childcare) and child BMI centile at 5 years, which accounts for sex and age. Similar methods were used for determining associations with breastfeeding duration as the predictor of child eating behaviours, and maternal eating behaviours as the predictor of child eating behaviours. Spearman Rho was used to determine correlations between breastfeeding duration and child eating behaviours. Pearson correlations determined initial unadjusted associations between maternal and child eating behaviours. Those with a correlation $p$ value of $<0.05$ were further analysed using multiple regression models. Models were adjusted for original RCT group, maternal education level, maternal BMI at 5 years, breastfeeding exposure, childcare exposure and child BMI centile at 5 years. Models with $p<0.05$ were considered significant.

\section{Results}

This analysis included 230 mother-child dyads of the ROLO 5-year follow-up; 105 were male (45.7\%). There were $123(53.5 \%)$ mothers in the intervention group of the RCT. Eighty-three per cent had achieved some third-level education and most children (91\%) had been exposed to childcare.

Of those that returned at 5 years, $68.7 \%$ had breastfed their child. Of mothers that breastfed, median breastfeeding duration was 22 weeks (IQR: 33.00). Mean scores for childhood eating behaviours were as follows: $12.59 \pm 4.05$ for 'food responsiveness', $6.62 \pm 1.99$ for 'emotional overeating', $15.20 \pm 2.91$ for 'enjoyment of food', $8.05 \pm 2.74$ for 'desire to drink', $15.18 \pm 3.24$ for 'satiety responsiveness', $12.14 \pm 3.18$ for 'slowness in eating', $10.92 \pm 3.36$ for 'emotional undereating' and finally $18.41 \pm 5.90$ for 'food fussiness'. For maternal eating behaviours, average scores were $18.17 \pm 4.87$ for 'uncontrolled eating', $6.67 \pm 2.55$ for 'emotional eating' and $13.93 \pm 3.18$ for 'cognitive restraint'. Further details on demographics are reported in Table 1.

\section{Breastfeeding exposure and child eating behaviours}

Children that had any exposure to breastfeeding were less likely to express a 'desire to drink' than those that had not been breastfed (7.77 vs. $8.65, p=0.023)$ in unadjusted
Table $1 \mathrm{ROLO}^{\mathrm{a}}$ participant characteristics, breastfeeding habits and mean eating behaviour scores at 5 years of age.

\begin{tabular}{|c|c|c|}
\hline \multicolumn{3}{|l|}{ Maternal characteristics } \\
\hline Age (years, mean, SD) & 38.52 & 3.95 \\
\hline Ethnicity (White, Irish; $n, \%$ ) & 212 & 92.20 \\
\hline $\mathrm{BMI}^{\mathrm{a}}$ at 5 years $\left(\mathrm{kg} / \mathrm{m}^{2}\right.$; median, IQR $)$ & 25.62 & 4.54 \\
\hline High education level $^{\mathrm{a}}(n, \%)$ & 178 & 83.20 \\
\hline ROLO RCT ${ }^{\mathrm{a}}$ group-intervention $(n, \%)$ & 123 & 53.50 \\
\hline \multicolumn{3}{|l|}{ Maternal eating behaviours-TFEQ } \\
\hline Uncontrolled eating (mean, SD) & 18.17 & 4.87 \\
\hline Emotional eating (mean, SD) & 6.67 & 2.55 \\
\hline Cognitive restraint (mean, SD) & 13.93 & 3.18 \\
\hline \multicolumn{3}{|l|}{ Breastfeeding habits } \\
\hline Breastfeeding ever (yes, $n, \%$ ) & 158 & 68.70 \\
\hline Breastfeeding duration (weeks; median, IQR) & 21.67 & 33.00 \\
\hline \multicolumn{3}{|l|}{ Child characteristics } \\
\hline Sex (males; $n, \%$ ) & 105 & 45.70 \\
\hline Age (years; median, IQR) & 5.12 & 0.15 \\
\hline Birthweight (kg; mean, SD) & 4.00 & 0.44 \\
\hline Birthweight centile (median, IQR) & 72.09 & 24.42 \\
\hline BMI at 5 years $\left(\mathrm{kg} / \mathrm{m}^{2 ;}\right.$ mean, SD) & 16.18 & 1.33 \\
\hline BMI centile at 5 years (median, IQR) & 61.87 & 25.34 \\
\hline Attended childcare (yes; $n, \%$ ) & 209 & 90.90 \\
\hline \multicolumn{3}{|l|}{ Child eating behaviours-CEBQ } \\
\hline Food responsiveness (mean, SD) & 12.59 & 4.05 \\
\hline Emotional overeating (mean, SD) & 6.62 & 1.99 \\
\hline Enjoyment of food (mean, SD) & 15.2 & 2.91 \\
\hline Desire to drink (mean, SD) & 8.05 & 2.74 \\
\hline Satiety responsiveness (mean, SD) & 15.18 & 3.24 \\
\hline Slowness in eating (mean, SD) & 12.14 & 3.18 \\
\hline Emotional undereating (mean, SD) & 10.92 & 3.36 \\
\hline Food fussiness (mean, SD) & 18.41 & 5.90 \\
\hline
\end{tabular}

$n=230$.

${ }^{\mathrm{a}} R O L O$ a randomised control trial of low glycaemic index diet to prevent macrosomia in euglycaemic women [22], BMI body mass index, $I Q R$ interquartile range, High Education level education from a higher education institute (universities, institutes of technology and colleges of education), RCT randomised control trial, TFEQ Three Factor Eating Questionnaire, CEBQ Child Eating Behaviour Questionnaire.

analysis. No other significant differences were identified. Further details can be seen in Table 2 .

Multiple regression analyses were carried out to adjust for confounding factors, including RCT group, maternal education level, maternal BMI, childcare exposure and child BMI centile at 5-year follow-up. The association between no breastfeeding exposure and increased 'desire to drink' remained in the adjusted analysis $(B=-1.01, p=0.022)$ (Table 3). 
Breastfeeding duration and child eating behaviours

Correlations between breastfeeding duration (weeks) and child eating behaviours were determined in unadjusted analysis. Breastfeeding duration was significantly associated with 'food responsiveness' $(B=-0.21, p=0.012)$, 'desire to drink' $(B=-0.18, p=0.030)$ and 'emotional undereating' $(B=0.20, p=0.015)$. No other eating behaviours were significantly correlated with breastfeeding duration.

Significant correlations between breastfeeding duration (weeks) and child eating behaviours at 5 years of age were further investigated, adjusted for RCT group, maternal education level, maternal BMI, childcare exposure and child BMI centile at 5-year follow-up. 'Food responsiveness' was negatively, significantly associated with longer breastfeeding duration $(B=-1.71, p=0.003)$ (Table 4).

\section{Maternal eating behaviours and child eating behaviours}

In unadjusted analysis, maternal 'uncontrolled eating' was significantly associated with child 'food responsiveness'

Table 2 Independent sample $t$-tests to determine differences in child eating behaviours at 5 years of age between breastfeeding exposure groups.

\begin{tabular}{|c|c|c|c|c|c|}
\hline \multirow[t]{2}{*}{ Child eating behaviour } & \multicolumn{2}{|c|}{$\begin{array}{l}\text { Breastfed } \\
(n=158)\end{array}$} & \multicolumn{2}{|c|}{$\begin{array}{l}\text { Never } \\
\text { Breastfed } \\
(n=72)\end{array}$} & \multirow[t]{2}{*}{$p$} \\
\hline & Mean & $\mathrm{SD}^{\mathrm{a}}$ & Mean & SD & \\
\hline Food responsiveness & 12.54 & 3.95 & 12.68 & 4.30 & 0.814 \\
\hline Emotional overeating & 6.63 & 2.12 & 6.60 & 1.72 & 0.911 \\
\hline Enjoyment of food & 15.26 & 2.67 & 15.06 & 3.39 & 0.653 \\
\hline Desire to drink & 7.77 & 2.63 & 8.65 & 2.89 & 0.023 \\
\hline Satiety responsiveness & 15.42 & 3.32 & 14.64 & 3.02 & 0.088 \\
\hline Slowness in eating & 12.26 & 3.15 & 11.89 & 3.25 & 0.413 \\
\hline Emotional undereating & 11.15 & 3.33 & 10.42 & 3.37 & 0.127 \\
\hline Food fussiness & 18.27 & 5.74 & 18.71 & 6.28 & 0.604 \\
\hline
\end{tabular}

Significant $p$ value $<0.05$.

${ }^{\text {a }} S D$ standard deviation.
$(B=0.24, p<0.001)$, 'emotional overeating' $(B=0.31$, $p<0.001)$, 'desire to drink' $(B=0.14, p=0.026)$ and 'emotional undereating' $(B=0.22, p=0.001)$. Maternal 'emotional eating' was associated with 'emotional overeating' $(B=0.27, p<0.001)$, 'satiety responsiveness' $(B=0.20$, $p=0.002)$, 'food fussiness' $(B=0.18, p=0.006)$ and 'emotional undereating' $(B=0.23, p=0.001)$.

After adjusting models for confounders (RCT group, maternal education level, maternal BMI, childcare exposure and child BMI centile at 5 years), significant associations were found between maternal and child eating behaviours. Maternal 'uncontrolled eating' was positively associated with child 'food responsiveness' $(B=0.21, p<0.001)$, 'emotional overeating' $(B=0.14, p=0.005)$ and 'emotional undereating' $(B=0.14, p=0.005)$. Maternal 'emotional eating' was positively associated with child 'emotional overeating' $(B=0.27, \quad p<0.001)$, 'satiety responsiveness' $(B=0.25, p=0.009)$, 'emotional undereating' $(B=0.29, p=0.004)$ and 'food fussiness' $(B=$ $0.58, p=0.001)$ (Table 5).

\section{Discussion}

This analysis found breastfeeding practices and maternal eating behaviours to be significantly associated with child eating behaviours at 5 years of age. Children that were breastfed at all were less likely to express a desire to drink sugary drinks. Children that were breastfed for longer were less likely to demonstrate food responsiveness and a desire to drink. We found that an increase in uncontrolled eating in mothers was associated with an increase in child food responsiveness and emotional overeating and undereating. Similarly, an increase in maternal emotional eating scores was associated with an increase in child emotional overeating and undereating, picky eating and responses to internal satiety cues.

\section{Breastfeeding and child eating behaviours}

Sixty-eight per cent of women in this analysis had initiated breastfeeding with $37 \%$ of these women breastfeeding for
Table 3 Adjusted multiple regression models with exposure to breastfeeding as the predictor and child eating behaviours as the outcome variable.

\begin{tabular}{|c|c|c|c|c|c|c|}
\hline \multirow[t]{2}{*}{ Models $^{\mathrm{a}}$} & \multirow[t]{2}{*}{$\mathrm{B}$} & \multirow[t]{2}{*}{$p$} & \multirow[t]{2}{*}{ Adjusted $\mathrm{R}^{2}$} & \multicolumn{2}{|c|}{$\begin{array}{l}95 \% \text { confidence } \\
\text { interval }\end{array}$} & \multirow[t]{2}{*}{$p$} \\
\hline & & & & Lower & Upper & \\
\hline \multicolumn{7}{|l|}{ Desire to drink } \\
\hline Breastfeeding exposure & -1.008 & 0.022 & 0.025 & -1.871 & -0.144 & 0.088 \\
\hline
\end{tabular}


Table 4 Multiple regression analysis between breastfeeding duration (weeks) as predictor and child eating behaviours at 5 years of age as outcome variables.

Table 5 Multiple regression analysis with maternal eating behaviours as predictor of child eating behaviours at 5 years of age.

\begin{tabular}{|c|c|c|c|c|c|c|}
\hline & \multirow[t]{2}{*}{$\mathrm{B}$} & \multirow[t]{2}{*}{$p$} & \multirow[t]{2}{*}{ Adjusted $\mathrm{R}^{2}$} & \multicolumn{2}{|c|}{$\begin{array}{l}95 \% \text { confidence } \\
\text { interval }\end{array}$} & \multirow[t]{2}{*}{$p$} \\
\hline & & & & Lower & Upper & \\
\hline \multicolumn{7}{|l|}{ Child food responsiveness } \\
\hline Breastfeeding duration $^{a}$ & -1.708 & 0.003 & 0.058 & -2.817 & -0.599 & 0.032 \\
\hline \multicolumn{7}{|l|}{ Child desire to drink } \\
\hline Breastfeeding duration $^{a}$ & -0.744 & 0.057 & 0.012 & -1.51 & 0.025 & 0.278 \\
\hline \multicolumn{7}{|l|}{ Child emotional undereating } \\
\hline Breastfeeding duration $^{a}$ & 0.950 & 0.046 & 0.058 & -0.016 & 1.883 & 0.140 \\
\hline \multicolumn{7}{|c|}{$\begin{array}{l}\text { Multiple regression analyses controlled for RCT group, maternal education level, maternal BMI, childcare } \\
\text { exposure and child BMI centile at } 5 \text { years. Significant } p<0.05, n=150 \text {. }\end{array}$} \\
\hline \multicolumn{7}{|c|}{$\begin{array}{l}{ }^{\mathrm{a} B r e a s t f e e d i n g ~ d u r a t i o n ~(p r e d i c t o r) ~ m e a s u r e d ~ i n ~ w e e k s . ~ C h i l d ~ e a t i n g ~ b e h a v i o u r s ~(o u t c o m e) ~ d e t e r m i n e c ~} \\
\text { using CEBQ. }\end{array}$} \\
\hline \multirow[t]{2}{*}{ Models } & \multirow[t]{2}{*}{ B } & \multirow[t]{2}{*}{$p$} & \multirow[t]{2}{*}{ Adjusted $\mathrm{R}^{2}$} & \multicolumn{2}{|c|}{$\begin{array}{l}95 \% \text { confidence } \\
\text { interval }\end{array}$} & \multirow[t]{2}{*}{$p$} \\
\hline & & & & Lower & Upper & \\
\hline \multicolumn{7}{|l|}{ Child food responsiveness } \\
\hline 1. Uncontrolled eating & 0.213 & $<0.001$ & 0.067 & 0.096 & 0.330 & 0.003 \\
\hline \multicolumn{7}{|l|}{ Child emotional overeating } \\
\hline 1. Uncontrolled eating & 0.141 & 0.005 & 0.052 & 0.044 & 0.239 & 0.011 \\
\hline 2. Emotional eating & 0.269 & $<0.001$ & 0.081 & 0.155 & 0.383 & 0.001 \\
\hline \multicolumn{7}{|l|}{ Child desire to drink } \\
\hline 1. Uncontrolled eating & 0.076 & 0.064 & 0.016 & -0.005 & 0.157 & 0.162 \\
\hline \multicolumn{7}{|l|}{ Child satiety responsiveness } \\
\hline 1. Emotional eating & 0.252 & 0.009 & 0.052 & 0.064 & 0.440 & 0.011 \\
\hline \multicolumn{7}{|l|}{ Child slowness in eating } \\
\hline 1. Emotional eating & 0.155 & 0.102 & 0.037 & -0.031 & 0.341 & 0.036 \\
\hline \multicolumn{7}{|l|}{ Child emotional undereating } \\
\hline 1. Uncontrolled eating & 0.141 & 0.005 & 0.052 & 0.044 & 0.239 & 0.011 \\
\hline 2. Emotional eating & 0.289 & 0.004 & 0.054 & 0.094 & 0.483 & 0.010 \\
\hline \multicolumn{7}{|l|}{ Child food fussiness } \\
\hline 1. Emotional eating & 0.577 & 0.001 & 0.049 & 0.235 & 0.920 & 0.014 \\
\hline
\end{tabular}

Significance determined using individual multiple linear regression models adjusted for RCT group, maternal education level, maternal BMI at 5 years, breastfeeding exposure, childcare exposure and child BMI centile at 5 years. Significant at $p<0.05, n=230$. Maternal eating behaviours (predictor) determined using TFEQ. Child eating behaviours (outcome) determined using CEBQ. the recommended 6 months. This is slightly higher than the WHO report, which reported an average of $23 \%$ of Irish mothers breastfed for 6 months [7]. The breastfeeding initiation rate is also slightly higher than that reported in 2017 which was $58 \%$ [31].

Previous studies including the Generation R Study and the Healthy Start Primary Intervention reported decreased fussy eating with longer breastfeeding duration [10, 11]. Our findings showed breastfeeding to have no association with fussy eating. Although in line with some previous studies, including the ALSPAC study [12], this was unexpected considering the importance of breastfeeding in developing the infants tastes and preferences for healthy foods [8]. Such contradictory evidence requires further studies to confirm the true association.

This is the first study to show that children that are not breastfed are more likely to have a constant want for drinks. Breastfeeding is thought to encourage infants to recognise internal satiety cues compared to bottle feeding, as breastfeeding is based on the infant's needs rather than the timing considered appropriate by the caregiver [32]. Our findings that breastfeeding reduces the desire to drink may add to this discussion as to how infant feeding can impact food and drink choices throughout childhood. 
Mother's that breastfed for shorter durations perceived their children to inappropriately respond to the food around them and to have a greater desire for drinks. These behaviours have previously been associated with children having overweight and/or obesity [5, 11, 33, 34]. Other research has hypothesised that this relationship is due to a child's ability to recognise a feeling of fullness, as breastfed infants learn to control their intakes better than formula fed infants $[14,35]$. Furthermore, we found longer breastfeeding duration to be associated with children eating less in times of emotional distress. This may be a result of infants having improved control over their intakes and not considering food as a source of comfort.

The relationship between breastfeeding and behaviours of over consumption may also be attenuated by hormones present in breastmilk, including leptin, adiponectin and ghrelin [36-38]. These hormones are involved in appetite regulation and therefore are potentially linked to infant eating behaviours and infant weight status. The negative association between breastfeeding and inappropriate responses to food may be due to increased exposure to such hormones with longer breastfeeding, hence the infants learns appropriate response to hunger and satiation. The complexity in understanding the development of eating behaviours is clear as we discuss our own findings in comparison to existing literature.

These findings indicate that the relationship between breastfeeding and lower childhood obesity could be mediated by eating behaviours, as a desire to drink and food responsiveness have previously been linked to overweight and obesity during childhood [5, 33, 39, 40].

\section{Relationship between mother and child eating behaviours}

It was found that maternal restrictive eating behaviours were not associated with her child's perceived eating behaviour, however, uncontrolled eating and emotional eating both had significant associations with various child eating behaviours. Cognitive restraint is indicative of dieting, which may be a habit adopted at a later stage than 5 years, hence no association was observed.

Uncontrolled eating is the response to external food cues in mothers, showing a lack of self-control and high appetitive motivation [41]. We found maternal uncontrolled eating to be associated with offspring's food responsiveness; mothers that find difficulty in resisting tempting foods had a child with similar obesogenic eating behaviours. Both uncontrolled eating and food responsiveness represent behaviours such as not being able to resist foods, excessive eating in times of distress and constant need to drink. These eating behaviours in children are indicative of an increased energy intake, particularly in our current obesogenic environment [42]. This indicates that children may emulate their mother's impulsive reactions towards their food and drink environment. Our findings are supported by a previous study involving 8-12-year-old German children with a BMI centile $\geq 85 \%$, which suggested a mother's increased food intake behaviour may influence her child's inability to self-regulate food impulses [43].

Such behaviours of increased desire to drink, inability to resist foods and excessive eating in emotional turmoil have been associated with increased child weight status in 7-12 years old across the UK, as shown by Webber et al. [5] using two cohorts: the PEACHES longitudinal and the TEDS cohort study. A mother's eating behaviour could instil similar, unfavourable eating habits in her child, which result in increased energy intake, contributing to the development of overweight and obesity. It is clear that eating behaviours require further investigations to fully understand their development, considering parental impacts.

The complexity of eating behaviours is further shown in the contradictory relationships between maternal uncontrolled eating and child emotional undereating. Maternal uncontrolled eating was positively associated with a child eating less when sad/anxious. It is also associated with a child eating more in these times. In children, these behaviours are correlated with each other, which indicates children that have a tendency to overeat similarly undereat when distressed [25, 44]. The understanding that children often display both overeating and undereating in varying times of emotional distress may explain how the behaviour of emotional overeating in mothers is associated with the opposing behaviour of emotional undereating in their child. The emotional overeating subscale also includes eating in times of boredom, which also has some loading on the food responsiveness subscale. With this in mind, it may not be a true association between uncontrolled eating and emotional eating; it could potentially be mediated by eating due to boredom. There is possibility that this requires its own subscale to further elucidate childhood eating behaviours effectively.

Maternal emotional eating implies a greater energy intake than usual during times of great stress or negative emotion [23]. Our study found maternal emotional eating to be positively and significantly associated with increased eating in times of negative emotions. This may be simply explained by a mirror effect as infants observe mothers consuming excess, palatable foods when upset, causing the child to associate food with a comforting mechanism. However, mothers that tend to overeat in times of distress also perceived their children to eat less in times of stress, to be picky eaters and to have increased responses to a feeling of fullness. It is unclear how such contradictory results may occur when investigating perceived eating behaviours. This area warrants further detailed research. 
In Ireland, strategies have been implemented to address the issue of childhood obesity, such as the SafeFood START Campaign [45]. Developing strategies that promote both breastfeeding and positive parental eating behaviours within the home could be a novel component of such public health campaigns with a goal of preventing childhood obesity. The START campaign does not currently address the topic of eating behaviours, nor do other similar public campaigns. Further research is necessary to determine if this is something that needs to be addressed.

\section{Strengths and limitations}

This study is strengthened by the use of validated questionnaires to measure eating behaviours of mothers and children. To our knowledge, it is the first study to utilise results of the TFEQ and the CEBQ to analyse relationships between eating behaviours of mothers and children and overall eating behaviours and breastfeeding practices. The use of a composite value for breastfeeding duration also increases the validity of the recall and reduces memory bias, and allows inclusion of mothers that may not have reported breastfeeding at each follow-up. All children in this analysis were the second eldest sibling in the family, as per inclusion criteria of the original ROLO study, thus limiting bias of family dynamics which may affect child eating behaviours. This study is not without limitations. Including only second-born children may also be a limitation, as a parent's perception of their first born child may be more concerned due to inexperience [46], hence giving different results in our parent-answered questionnaires. The CEBQ is a questionnaire regarding the child, intended to be reported by the primary caregiver. For this particular study, we only involved the mother. Therefore, if the mother is not the primary caregiver she is less likely to be fully aware of the child's eating habits. To mitigate this, we adjusted analysis for childcare exposure. The mother may have perceived eating behaviours in a way that is similar to her own, creating a type of bias within the questionnaire scores. This cohort is well-educated which may not be fully representative of other populations. This is a common issue among interventional studies and is difficult to completely eliminate, which should be considered when interpreting the results. We made efforts to reduce such bias by adjusting for education level.

Our research furthers our understanding of the importance of both initiation and longevity of breastfeeding. This adds to the discussion surrounding the positives of breastfeeding. Women should be encouraged to breastfeed if at all possible, for as long as possible. It is vital that women are provided with adequately funded public services to avail of to encourage positive breastfeeding practices. Research investigating childhood eating behaviours is of clinical importance as we continue to describe the complexities involved, and how they can contribute to childhood health. Investigating these behaviours can lead to a better understanding of how they develop in children, and how they may contribute to the aetiology of childhood overweight and obesity, potentially leading to novel advances in tackling this current global epidemic.

\section{Conclusion}

The findings of this study indicate that breastfeeding practices and positive maternal eating behaviours promote healthful child eating behaviours, known to influence child weight status. This further elucidates the benefits of breastfeeding, and how this extends right throughout childhood. It also adds to our understanding of parental involvement in the development of child eating behaviours.

Acknowledgements The authors would like to thank all the ROLO participants for their involvement and all the staff at the National Maternity Hospital, Dublin, Ireland.

Funding This study was supported by the Health Research Board Ireland, the Health Research Centre for Health and Diet Research, the National Maternity Hospital Medical Fund and the European Union's Seventh Framework Programme (FP7/2007-2013), project EarlyNutrition under Grant Agreement No. 289346.

Author contributions FMMA, AAG, ECOB and CAY were responsible for the project conception. CAY, AAG, MKH and FMMA designed the research and the analysis plan. CAY, AAG, ECOB, $\mathrm{MKH}, \mathrm{JMD}, \mathrm{SLK}$ and EL conducted the research and carried out data collection. JM collated the database and computed new data. CAY analysed data and performed statistical analysis. CAY wrote the paper and all authors critically reviewed and approved the final paper.

\section{Compliance with ethical standards}

Conflict of interest The authors declare that they have no conflict of interest.

Ethical approval Ethical approval for this study was granted by the Ethics Committee of the National Maternity Hospital and Our Lady's Children Hospital, Crumlin, Reference GEN/279/12.

Informed consent Written informed consent was obtained from all individuals prior to participating in the research study.

Publisher's note Springer Nature remains neutral with regard to jurisdictional claims in published maps and institutional affiliations.

Open Access This article is licensed under a Creative Commons Attribution 4.0 International License, which permits use, sharing, adaptation, distribution and reproduction in any medium or format, as long as you give appropriate credit to the original author(s) and the source, provide a link to the Creative Commons license, and indicate if changes were made. The images or other third party material in this article are included in the article's Creative Commons license, unless 
indicated otherwise in a credit line to the material. If material is not included in the article's Creative Commons license and your intended use is not permitted by statutory regulation or exceeds the permitted use, you will need to obtain permission directly from the copyright holder. To view a copy of this license, visit http://creativecommons. org/licenses/by/4.0/.

\section{References}

1. Irish Universities Nutrition Alliance (IUNA) (2019) National Children's Food Survey II: Summary Report. Available online at http://www.iuna.net/.

2. Safefood. Body weight and eating habits in 5-12 year old Irish children. Safefood; 2011. pp. 1-31. https://www.safefood.net/ research-reports/body-weight-eating-habits-kids.

3. Jansen PW, Roza SJ, Jaddoe VW, Mackenbach JD, Raat H, Hofman A, et al. Children's eating behavior, feeding practices of parents and weight problems in early childhood: results from the population-based Generation R Study. Int J Behav Nutr Phys Act. 2012;9:130.

4. Quah PL, Fries LR, Chan MJ, Fogel A, McCrickerd K, Goh AT, et al. Validation of the Children's Eating Behavior Questionnaire in 5 and 6 year-old children: the GUSTO Cohort Study. Front Psychol. 2019;11:10.

5. Webber L, Hill C, Saxton J, Jaarsveld CHMV, Wardle J. Eating behaviour and weight in children. Int J Obes. 2009;33:21-8.

6. Unicef. Global strategy for infant and young child feeding. Geneva: World Heal Organisation; 2003. pp. 1-5.

7. Rito AI, Buoncristiano M, Spinelli A, Salanave B, Kunešová M, Hejgaard T, et al. Association between characteristics at birth, breastfeeding and obesity in 22 countries: the WHO European Childhood Obesity Surveillance Initiative-COSI 2015/2017. Obes Facts. 2019;12:226-43.

8. Ventura AK. Does breastfeeding shape food preferences? Links to obesity. Ann Nutr Metab. 2017;70:8-15.

9. Galloway AT, Lee Y, Birch LL. Predictors and consequences of food neophobia and pickiness in young girls. J Am Diet Assoc. 2003;103:692-8.

10. Heitmann BL, Olsen NJ, Rohde JF, Specht IO. Duration of exclusive breastfeeding may be related to eating behaviour and dietary intake in obesity prone normal weight young children. PLOS ONE. 2018;13:1-12.

11. de Barse LM, Jansen PW, Edelson-Fries LR, Jaddoe VWV, Franco $\mathrm{OH}$, Tiemeier $\mathrm{H}$, et al. Infant feeding and child fussy eating: the Generation R Study. Appetite. 2017;114:374-81.

12. Emmett PM, Hays NP, Taylor CM. Antecedents of picky eating behaviour in young children. Appetite. 2018;130:163-73.

13. McDermott BM, Mamun AA, Najman JM, Williams GM, O'Callaghan MJ, Bor W. Preschool children perceived by mothers as irregular eaters: physical and psychosocial predictors from a Birth cohort study. J Dev Behav Pediatr. 2008;29:197-205.

14. Rogers SL, Blissett J. Breastfeeding duration and its relation to weight gain, eating behaviours and positive maternal feeding practices in infancy. Appetite. 2017;108:399-406.

15. Birch LL, Fisher JO. Development of eating behaviors among children and adolescents. Pediatrics. 1998;101:539-49.

16. Scaglioni S, Arrizza C, Vecchi F, Tedeschi S. Determinants of children's eating behavior. Am J Clin Nutr. 2011;94:S2006-11.

17. Johannsen DL, Johannsen NM, Specker BL. Influence of parents' eating behaviors and child feeding practices on children's weight status. Obesity. 2006;14:431-9.

18. Zocca JM, Shomaker LB, Tanofsky-Kraff M, Columbo KM, Raciti GR, Brady SM, et al. Links between mothers' and children's disinhibited eating and children's adiposity. Appetite. 2011;56:324-31.

19. De Lauzon-guillain B, Romon M, Musher-eizenman D, Heude B, Basdevant A, Charles M, et al. Cognitive restraint, uncontrolled eating and emotional eating: correlations between parent and adolescent: familial resemblance in eating behavior. Matern Child Nutr. 2009;5:171-8.

20. Walsh JM, McGowan CA, Mahony R, Foley ME, McAuliffe FM. Low glycaemic index diet in pregnancy to prevent macrosomia (ROLO study): randomised control trial. Br Med J. 2012;345: e5605.

21. Walsh JM, McGowan CA, Mahony R, Foley ME, McAuliffe FM. Low glycaemic index diet in pregnancy to prevent macrosomia (ROLO study): randomised control trial. World Rev Nutr Dietetics. 2014;109:101-2.

22. Stunkard A, Messick S. The three-factor eating questionnaire to measure dietary restraint, disinhibition and hunger. J Psychosom Res. 1985;29:71-83.

23. Anglé S, Engblom J, Eriksson T, Kautiainen S, Saha M-T, Lindfors P, et al. Three Factor Eating Questionnaire-R18 as a measure of cognitive restraint, uncontrolled eating and emotional eating in a sample of young Finnish females. Int J Behav Nutr Phys Act. 2009;6:41.

24. Karlsson J, Persson LO, Sjöström L, Sullivan M. Psychometric properties and factor structure of the Three-Factor Eating Questionnaire (TFEQ) in obese men and women. Results from the Swedish Obese Subjects (SOS) study. Int J Obes Relat Metab Disord. 2000;24:1715-25.

25. Wardle J, Guthrie CA, Sanderson S, Rapoport L. Development of the Children's Eating Behaviour Questionnaire. J Child Psychol Psychiatry. 2001;42:963-70.

26. Svensson V, Lundborg L, Cao Y, Nowicka P, Marcus C, Sobko T, et al. Obesity related eating behaviour patterns in Swedish preschool children and association with age, gender, relative weight and parental weight - factorial validation of the Children's Eating Behaviour Questionnaire. Int J Behav Nutr Phys Act. 2011;8:134.

27. Carnell S, Wardle J. Measuring behavioural susceptibility to obesity: validation of the Child Eating Behaviour Questionnaire. Appetite. 2007;48:104-13.

28. Domoff SE, Miller AL, Kaciroti N, Lumeng JC. Validation of the Children's Eating Behaviour Questionnaire in a low-income preschool-aged sample in the United States. Appetite. 2015;95: 415-20.

29. Gardosi J, Francis A, Turner S, Williams M. Customized growth charts: rationale, validation and clinical benefits. Am J Obstet Gynecol. 2018;218:S609-18.

30. Cole TJ, Freeman JV, Preece MA. Body mass index reference curves for the UK, 1990. Arch Dis Child. 1995;73:25-9.

31. Purdy J, McAvoy H, Cotter N. Breastfeeding on the island of Ireland. Dublin: Institute of Public Health in Ireland. 2017:1-42.

32. Savage J, Fisher J, Birch L. Parental influences on eating behavior: conception to adolescence. $\mathrm{J}$ Law Med Ethics. 2007;35:22-34.

33. French SA, Epstein LH, Jeffery RW, Blundell JE, Wardle J. Eating behavior dimensions. Associations with energy intake and body weight. A review. Appetite. 2012;59:541-9.

34. Gigante DP, Maciel FV, Matijasevich A. Children's eating behavior: comparison between normal and overweight children from a school in Pelotas, Rio Grande do Sul, Brazil. Rev Paul Pediatr. 2015;33:42-9.

35. Brown A, Lee M. Breastfeeding during the first year promotes satiety responsiveness in children aged 18-24 months. Pediatr Obes. 2012;7:382-90.

36. Casabiell X, Piñeiro V, Tomé MA, Peinó R, Dieguez C, Casanueva FF. Presence of leptin in colostrum and/or breast milk from 
lactating mothers: a potential role in the regulation of neonatal food intake. J Clin Endocrinol Metab. 1997;82:4270-3.

37. Martin LJ, Woo JG, Geraghty SR, Altaye M, Davidson BS, Banach $\mathrm{W}$, et al. Adiponectin is present in human milk and is associated with maternal factors. Am J Clin Nutr. 2006;83:1106-11.

38. Aydin S, Aydin S, Ozkan Y, Kumru S. Ghrelin is present in human colostrum, transitional and mature milk. Peptides. 2006;27:878-82.

39. Sánchez U, Weisstaub G, Santos JL, Corvalán C, Uauy R. GOCS cohort: children's eating behavior scores and BMI. Eur J Clin Nutr. 2016;70:925-8.

40. Braet C, Van Strien T. Assessment of emotional, externally induced and restrained eating behaviour in nine to twelve-year-old obese and non-obese children. Behav Res Ther. 1997;35:863-73.

41. Vainik U, Neseliler S, Konstabel K, Fellows LK, Dagher A. Eating traits questionnaires as a continuum of a single concept. Uncontrolled eating. Appetite. 2015;90:229-39.
42. Sleddens EF, Kremers SP, Thijs C. The Children's Eating Behaviour Questionnaire: factorial validity and association with Body Mass Index in Dutch children aged 6-7. Int J Behav Nutr Phys Act. 2008;5:49.

43. Munsch S, Hasenboehler K, Meyer AH. Is amount of food intake in overweight and obese children related to their psychopathology and to maternal eating behavior? $\mathrm{J}$ Psychosom Res. 2011;70:362-7.

44. Herle M, Fildes A, Steinsbekk S, Rijsdijk F, Llewellyn CH. Emotional over- and under-eating in early childhood are learned not inherited. Sci Rep. 2017;7:9092.

45. Safefood. Safefood START campaign. https://www.safefood.eu/ Start/Welcome.aspx (2017).

46. Emmett P, Hays N, Taylor C. Factors associated with maternal worry about her young child exhibiting choosy feeding behaviour. Int J Environ Res Public Health. 2018;15:1236. 